\title{
Silphiperfolene-Type Terpenoids and Other Metabolites from Cultures of the Tropical Ascomycete Hypoxylon rickii (Xylariaceae)
}

\author{
Frank Surup • Eric Kuhnert • Elena Liscinskij • \\ Marc Stadler
}

Received: 9 May 2015/ Accepted: 31 May 2015/Published online: 16 June 2015

(C) The Author(s) 2015. This article is published with open access at Springerlink.com

\begin{abstract}
A culture isolated from ascospores of Hypoxylon rickii, a xylariaceous ascomycete collected in Martinique, had yielded botryane, noreremophilane and abietane-type terpenoids in a preceding study, but additional metabolites were detected by extensive HPLC-MS analysis in other fractions. Herein we report the further isolation of four new sesquiterpenoids with a silphiperfol-6-ene skeleton from extracts of $H$. rickii. The planar structures were elucidated by NMR and HRMS data as 13-hydroxysilphiperfol-6-ene (1), 9-hydroxysilphiperfol-6-en-13-oic acid (2), 2-hydroxysilphiperfol-6-en13-oic acid (3) and 15-hydroxysilphiperfol-6-en-13-oic acid (4). For compounds 2-4 we propose the trivial names rickinic acids A-C. Their stereochemistry was assigned by ROESY correlations as well as by the specific optical rotation. Additionally, the known compounds, botryenanol, dehydrobotrydienol, cyclo(Phe-Pro), cyclo(Pro-Leu), (+)-ramulosin and $\alpha$ eleostearic acid were isolated. The antimicrobial and cytotoxic activities of the new compounds are also reported.
\end{abstract}

Graphical Abstract

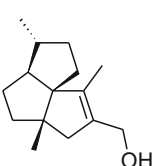

1

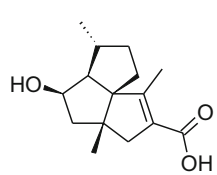

3

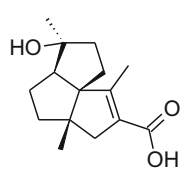

2

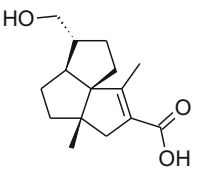

4

Keywords Hypoxylon $\cdot$ Xylariaceae $\cdot$ Natural products $\cdot$ Secondary metabolites $\cdot$ Structure elucidation

Electronic supplementary material The online version of this article (doi:10.1007/s13659-015-0065-3) contains supplementary material, which is available to authorized users.

F. Surup · E. Kuhnert · E. Liscinskij · M. Stadler $(\bowtie)$

Department Microbial Drugs, Helmholtz Centre for Infection

Research GmbH, Inhoffenstraße 7, 38124 Braunschweig,

Germany

e-mail: marc.stadler@helmholtz-hzi.de
F. Surup · E. Kuhnert - M. Stadler

German Centre for Infection Research (DZIF), Partner Site

Hannover-Braunschweig, 38124 Braunschweig, Germany 


\section{Introduction}

The exploration of the highly diverse fungal family Xylariaceae in terms of secondary metabolite production has revealed a tremendous amount of natural products from most of the biosynthetic pathways. Whereas polyketides and PKSNRPS hybrid molecules occur in the stromata [1-6] and cultures of the family members [7,8], terpenes were so far exclusively reported from cultures. Important examples of the latter structural class produced by the Xylariaceae are the antifungal sordarins from Rosellinia and Hypoxylon spp. [9], the neuropeptide gamma receptor antagonists, xylarenals A and B from Xylaria [10], the phytotoxic hymatoxins from "Hypoxylon" (current name Entoleuca) mammatum [11], the antihypertensive vinigrol from Virgaria [12], the antibacterial hypocoprins from Hypocopra [13], or botryanes from Daldinia concentrica [14].

Although the genus Hypoxylon is one of the largest within the Ascomycota and its representatives are frequently encountered as endophytes, little is known about their secondary metabolite production capabilities in cultures. Recently, we evaluated the diversity of natural products produced by the ex-epitype strain of $H$. rickii. Subsequently, various terpenoids of the botryane, noreudesmane and abietane scaffold were isolated from a single large scale fermentation of the strain [15]. We now report the isolation, structure elucidation and biological activity of four new silphiperfolene-type terpenoids and six known natural products from the same fungus.

\section{Results and Discussion}

A $70 \mathrm{~L}$ fermentation of a $\mathrm{H}$. rickii strain was processed by separating the mycelia from the culture broth and extraction of the corresponding biomass with acetone. The crude extract was pre-fractionized by MPLC and we focused on the isolation of the hydrophobic components by using HPLC. Besides several not further characterized fatty acids, we isolated the new metabolite 1 (Fig. 1) by subsequent HPLC. Compound 1 was obtained as a colorless oil; its molecular formula $\mathrm{C}_{15} \mathrm{H}_{24} \mathrm{O}$ was deduced from the molecular ion cluster $[\mathrm{M}+\mathrm{H}]^{+}$at $m / z 219.1737$ in the HRESIMS spectrum, which is implying 4 degrees of unsaturation. Proton and ${ }^{1} \mathrm{H},{ }^{13} \mathrm{C}$-HSQC NMR experiments revealed the presence of three methyls, six methylenes (one of which was oxygenated) and two methines. Furthermore, the carbon NMR spectrum suggested two $s p^{2}$ hybridized and two $s p^{3}$ hybridized quaternary carbons. The structural backbone of $\mathbf{1}$ was determined by ${ }^{1} \mathrm{H},{ }^{1} \mathrm{H}$ COSY and ${ }^{1} \mathrm{H},{ }^{13} \mathrm{C}$ HMBC correlations. Starting form methyl $\mathrm{H}_{3}-15$ the extensive spin system $\mathrm{H}_{2}-11 / \mathrm{H}_{2}-10 / \mathrm{H}-9\left(\mathrm{H}_{3}-15\right) / \mathrm{H}-1 / \mathrm{H}_{2}-2 / \mathrm{H}_{2}-3$ was determined by ${ }^{1} \mathrm{H},{ }^{1} \mathrm{H}$ COSY and TOCSY correlations

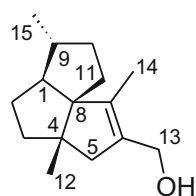

1

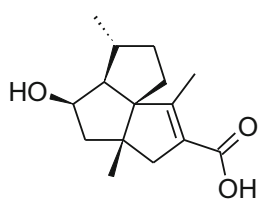

3

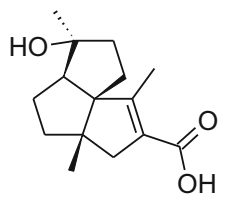

2

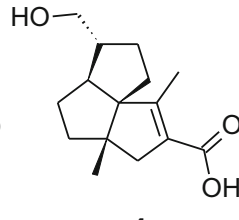

4
Fig. 1 Structures of new metabolites 1-4
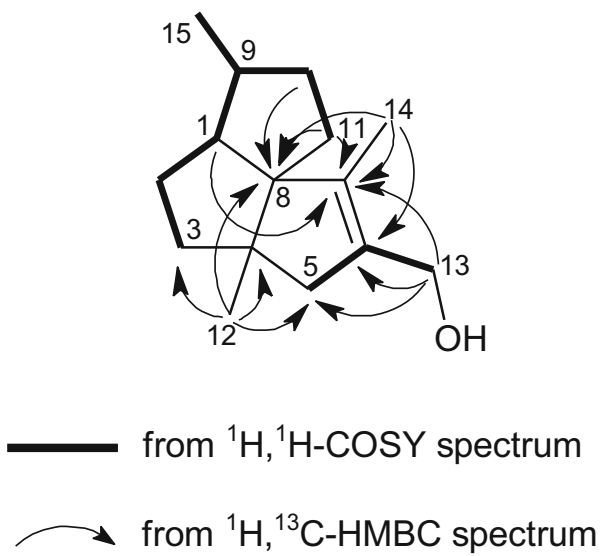

Fig. 2 Selected 2D NMR correlations of 1

(Fig. 2). By ${ }^{1} \mathrm{H},{ }^{13} \mathrm{C}$ HMBC correlations from methylenes $\mathrm{H}_{2}-5$ and $\mathrm{H}_{2}-13$ along with methyl $\mathrm{H}_{3}-14$ the C-5/C-6(C13)/C-7/C-14 partial structure was determined. Finally, ${ }^{1} \mathrm{H},{ }^{13} \mathrm{C}$ HMBC correlations from $\mathrm{H}-1, \mathrm{H}_{2}-2, \mathrm{H}_{2}-3, \mathrm{H}_{2}-5, \mathrm{H}_{2}-$ 9, $\mathrm{H}_{2}-10, \mathrm{H}_{2}-11, \mathrm{H}_{3}-12, \mathrm{H}_{3}-14$ to quaternary carbon $\mathrm{C}-8$ demonstrated the 13-hydroxysilphiperfol-6-ene structure. ${ }^{1} \mathrm{H},{ }^{1} \mathrm{H}$ ROESY correlations between $\mathrm{H}_{3}-15$ and $\mathrm{H}_{\beta}-11$ on the $\beta$-face and $\mathrm{H}_{3}-12$ and $\mathrm{H}_{\alpha}-11$ on the $\alpha$-face specify the typical $1 S^{*}, 4 S^{*}, 8 S^{*}, 9 R^{*}$ configuration of silphiperfolenetype sesquiterpenoids. Because compound $\mathbf{1}$ bears no additional optical centers, the negative specific optical rotation of $\mathbf{1}$ defines the absolute configuration as $1 S, 4 S, 8 S, 9 R$, since (-)-silphiperfol-6-ene has been synthesized from $(R)-(+)$-pulegone [16].

To provide additional material $H$. rickii was cultivated in $10 \mathrm{~L}$ scale in YM medium. 13-Hydroxysilphiperfol-6ene (1) could not be detected, but three oxidized derivatives (2-4) were isolated by preparative MPLC and HPLC. Metabolite $\mathbf{2}$ was obtained as a colorless oil; its molecular formula $\mathrm{C}_{15} \mathrm{H}_{22} \mathrm{O}_{3}$ was determined by the $[\mathrm{M}+\mathrm{H}]^{+}$ molecular ion cluster at $\mathrm{m} / \mathrm{z} 251.1649$ in the HRESIMS 
Fig. 3 Structures of known metabolites isolated from $H$. rickii<smiles>CC(=O)OC1CC(C)C(C=O)=C2C1C(C)(C)CC2(C)CO</smiles><smiles>O=C1NC(Cc2ccccc2)C(=O)N2CCCC12</smiles>

7<smiles>Cc1ccc2c(c1CO)C(C)(CO)CC2(C)C</smiles><smiles>CC(C)CC1NC(=O)C2CCCN2C1=O</smiles>

8<smiles>C[C@@H]1C[C@H]2CCCC(O)=C2C(=O)O1</smiles><smiles>CC/C=C/C=C\C=C/CCCCCCCC(=O)O</smiles>

10 spectrum. The main difference in the proton spectrum of 2 compared to $\mathbf{1}$ was the shortfall of signals for methine H-9 and methylene $\mathrm{H}_{2}-13$. This result was confirmed by the carbon spectrum, in which additional signals for a carboxyl and oxygenated quaternary $s p^{3}$ hybridized carbon atoms were observed. ${ }^{1} \mathrm{H},{ }^{13} \mathrm{C}$ HMBC correlations from $\mathrm{H}_{2}-5$ to $\mathrm{C}-13$ identified the carboxylic acid carbon atom as $\mathrm{C}-13$. Singulet methyl $\mathrm{H}_{3}-15$ showed ${ }^{1} \mathrm{H},{ }^{13} \mathrm{C}$ HMBC correlations to oxygen bearing C-9 besides C-1 and C-10. Therefore, 2 was identified as 9-hydroxysilphiperfol-6-en-13-oic acid. The configuration of stereocenter C-9 was assigned as $S$ as a consequence of the ${ }^{1} \mathrm{H},{ }^{1} \mathrm{H}$ ROESY correlation between methyls $\mathrm{H}_{3}-15$ and $\mathrm{H}_{3}-14$. This correlation demonstrates that the oxygenation occurred with retention of the configuration of methyl group $\mathrm{CH}_{3}-15$. 2 was named rickinic acid A.

Rickinic acid B (3) has the same molecular formula $\mathrm{C}_{15} \mathrm{H}_{22} \mathrm{O}_{3}$ as 2 , which was obtained by HRESIMS data. Proton, carbon and ${ }^{1} \mathrm{H},{ }^{13} \mathrm{C}$ HSQC NMR spectra were highly similar to that of 2 . However, the key differences were the replacement of the methylene signal for C-2 by an oxygenated methine, and the replacement of oxygenated quaternary carbon $\mathrm{C}-9$ by a methine. Therefore, 3 was identified as 2-hydroxysilphiperfol-6-en-13-oic acid. The ${ }^{1} \mathrm{H},{ }^{1} \mathrm{H}$ ROESY correlations from $\mathrm{H}-2$ to $\mathrm{H}-1 / \mathrm{H}_{\beta}-3$ and $\mathrm{H}_{\beta}-5$ on the $\beta$-face respectively from $\mathrm{H}_{3}-12$ to $\mathrm{H}_{\alpha}-3$ and $\mathrm{H}_{\alpha}-5$ on the $\alpha$-face of the molecule indicated a $2 R$ configuration.

With rickinic acid $\mathrm{C}(4)$ another metabolite was isolated with a $\mathrm{C}_{15} \mathrm{H}_{22} \mathrm{O}_{3}$ molecular formula. The proton and ${ }^{1} \mathrm{H},{ }^{13} \mathrm{C}$ HSQC NMR spectra showed the oxidation of methyl $\mathrm{CH}_{3}-15$ to a hydroxymethyl group, thus identifying 4 as 15-hydroxysilphiperfol-6-en-13-oic acid.

Besides the new metabolites 1-4, we isolated several known metabolites (Fig. 3) botryenanol (5), dehydrobotrydienol (6), cyclo(Phe-Pro) (7), cyclo(Pro-Leu) (8), $(+)$-ramulosin (9) and $\alpha$-eleostearic acid (10) from different cultivations of $H$. rickii [17-22].
The bioactivity of 1-4 was evaluated against $S$. cerevisiae, C. albicans, B. subtilis, E. coli and the mouse fibroblast cell line L929. We detected weak antifungal activity of $\mathbf{2}$ against the yeast $S$. cerevisiae ( $\mathrm{MIC}=66.7 \mu \mathrm{g} / \mathrm{mL})$, weak antibacterial activity of 4 against B. subtilis (MIC $=33.3 \mu \mathrm{g} / \mathrm{mL}$ ) and weak cytotoxic activity of $3\left(\mathrm{IC}_{50}=20 \mu \mathrm{g} / \mathrm{mL}\right)$.

The sesquiterpenoids $\mathbf{1 - 4}$ belong to a family of compounds with a silphiperfolene core structure. These compounds are known to be produced by members of the plant family Asteraceae [23, 24]. However, no fungal metabolite with this particular core structure has been described to the best of our knowledge. The role of these metabolites for $H$. rickii in nature remains elusive. The compounds might be produced to modulate its host plant, similarly to the fungal production of gibberellin-type phytohormons [25]. Though, the silphiperfolene metabolites might also be side products in the biosynthesis of botryanes. Presilphiperfolanol has been proposed as precursor of triquinane [26] as well as botryane [27] type sesquiterpenes. Even though presilphiperfolanol as potential common precursor has not been detected so far, this might explain the co-occurrence of silphiperfolene and botryane-type metabolites in cultures of $H$. rickii.

The identification of compounds $\mathbf{5}$ and $\mathbf{6}$ continues the list of known botryane-type terpenoids from $\mathrm{H}$. rickii [15]. This class of secondary metabolites has already been reported from other xylariaceous fungi like Daldinia concentrica and a Geniculisporium sp. [14, 28] and seems therefore common within the family. The same is true for the isocoumarin derivative (+)-ramulosin (9) which frequently occurs in the genus Hypoxylon [29]. The latter has been shown to exhibit phytotoxic and antifungal effects [30]. The production of diketopiperazines in the Xylariaceae is so far only known from Rosellinia necatrix [31] and therefore $\mathbf{7}$ and $\mathbf{8}$ are the first report of this particular compound class from another member of the family. 


\section{Experimental}

\subsection{General Experimental Procedures}

Optical rotations were determined with a Perkin-Elmer 241 spectrometer and UV spectra were recorded with a Shimadzu UV-Vis spectrophotometer UV-2450. NMR spectra were recorded with Bruker Avance III 700 spectrometer with a $5 \mathrm{~mm}$ TCI cryoprobe $\left({ }^{1} \mathrm{H} 700 \mathrm{MHz},{ }^{13} \mathrm{C} 175 \mathrm{MHz}\right)$ and Avance III 500 (1H $500 \mathrm{MHz}, 13 \mathrm{C} 125 \mathrm{MHz}$ ) spectrometers. HRESIMS mass spectra were obtained as previously described [32]. Isolation of pure compounds was achieved if not indicated otherwise with a preparative HPLC (Gilson, Middleton, USA) equipped with a GX-271 Liquid Handler, a 172 DAD, a 305 and 306 pump (with 50SC Piston Pump Head). As stationary phase a VP Nucleodur C18 ec column $(125 \times 40 \mathrm{~mm}, 7 \mu \mathrm{m}$; Macherey-Nagel) was used. The mobile phase was composed of deionised water (Milli-Q, Millipore, Schwalbach, Germany) with $0.1 \%$ acetic acid (solvent A1; Roth) and acetonitrile (ACN) with $0.1 \%$ acetic acid (solvent $\mathrm{B} 1$ ). Flow rate was set to $15 \mathrm{ml} / \mathrm{min}$.

\subsection{Fungal Material}

Stromata (fruiting bodies) of $H$. rickii MJF10324 were collected in 2010 from the Caribbean island Martinique by J. Fournier. The strain was designated as epitype of the species [33]. The culture was derived by multispore isolation on YMG medium (1.0\% malt extract, $0.4 \%$ glucose, $0.4 \%$ yeast extract, $\mathrm{pH}$ 6.3) using the method outlined by Stadler et al. [34] and has been deposited in public culture collections (MUCL 53309, CBS 129345).

\subsection{Cultivation in $70 \mathrm{~L}$ Scale and Isolation of $\mathbf{1}$ and $\mathbf{1 0}$}

Large-scale fermentation of the strain was carried out as previously described [14] in HLX media (3.0\% sucrose, $1.0 \%$ casamino acids, $0.1 \% \mathrm{~K}_{2} \mathrm{HPO}_{4}, 0.1 \%$ yeast extract, $0.05 \% \quad \mathrm{MgSO}_{4} \times 7 \mathrm{H}_{2} \mathrm{O}, \quad 0.05 \% \mathrm{KCl}, 0.001 \% \quad \mathrm{FeS}-$ $\left.\mathrm{O}_{4} \times 7 \mathrm{H}_{2} \mathrm{O}\right)$. The fermentation was aborted after 7 days as sugars (sucrose, fructose) were depleted. Compound $\mathbf{1}$ and 10 were obtained from the acetone crude extract of the biomass (12 g) by preparative RP MPLC and subsequent HPLC. The conditions for the RP MPLC were as follows: a ODS/AQ C18 column $(480 \times 30 \mathrm{~mm}$, Kronlab) as stationary phase, mobile phase composed of solvent A2 [90\% deionised water (Milli-Q), $10 \%$ methanol] and solvent B2 (methanol), linear gradient of solvent B2 from 10 to $100 \%$ in $60 \mathrm{~min}$, followed by isocratic conditions at $100 \%$ solvent $\mathrm{B} 2$ for $20 \mathrm{~min}$, flow rate of $30 \mathrm{ml} / \mathrm{min}$, UV peak detection at $210 \mathrm{~nm}$. Compound 1 (2 mg) was purified from the MPLC fraction with a retention time (RT) of
58.5-64.0 $\min (390 \mathrm{mg}$ ) using a linear gradient from 55 to $100 \%$ solvent B1 in 25 min followed by isocratic conditions at $100 \%$ for $15 \mathrm{~min}$ at a $\mathrm{RT}=26.0 \mathrm{~min}$. Compound 10 (RT: $14.0 \mathrm{~min} ; 2 \mathrm{mg}$ ) was isolated from another MPLC fraction (RT: 64.0-67.0 min; $1.8 \mathrm{~g}$ ) by RP HPLC (linear gradient from 90 to $100 \% \mathrm{~B} 1$ in $20 \mathrm{~min}$, followed by $15 \mathrm{~min}$ isocratic conditions).

13-Hydroxysilphiperfol-6-ene (1): amorphous powder, $[\alpha]_{\mathrm{D}}^{25}-29(c 0.2 \mathrm{MeOH}) ;{ }^{1} \mathrm{H}(700 \mathrm{MHz})$ and ${ }^{13} \mathrm{C}(175 \mathrm{MHz})$ NMR data (methanol- $d_{4}$ ), see Tables 1 and 2; HRESIMS: $m / z, 203.1791$ (calcd for $\mathrm{C}_{15} \mathrm{H}_{23},\left[\mathrm{M}+\mathrm{H}-\mathrm{H}_{2} 0\right]^{+}, 203.1794$ ), 219.1737 (calcd for $\mathrm{C}_{15} \mathrm{H}_{23} \mathrm{O},[\mathrm{M}+\mathrm{H}]^{+}, 219.1743$ ).

$\alpha$-Eleostearic acid (10): colorless oil; ${ }^{13} \mathrm{C}$ NMR (chloroform- $d, 125 \mathrm{MHz}) \delta 14.1,22.4,24.8,28.0,29.1,29.2,29.7$, 29.9, 31.5, 32.7, 33.9, 126.2, 129.0, 130.5, 132.1, 133.2, 135.5, 178.8; HRESIMS: $m / z 279.2319$ (calcd for $\mathrm{C}_{18} \mathrm{H}_{31} \mathrm{O}_{2}$, $\left.[\mathrm{M}+\mathrm{H}]^{+}, 279.2319\right)$; spectroscopic and spectrometric data are in good agreement with the literature [22].

\subsection{Cultivation in $10 \mathrm{~L}$ Scale and Isolation of $\mathbf{2 - 4}$ and 6-8}

A seed culture of the strain with a total volume of $200 \mathrm{~mL}$ was prepared in YMG medium $(1.0 \%$ malt extract, $0.4 \%$ glucose, $0.4 \%$ yeast extract, $\mathrm{pH} 6.3$ ), incubated at $22{ }^{\circ} \mathrm{C}$ and $140 \mathrm{rpm}$ for 5 days, homogenized with an ultratorax and incubated again for 2 days $\left(22^{\circ} \mathrm{C}, 140 \mathrm{rpm}\right)$. A BR 15.4 bioreactor (B. Braun Melsungen AG, Germany) filled with $10 \mathrm{~L}$ YMG medium and supplemented with $0.5 \%$ talcum powder (Sigma-Aldrich, St. Louis, USA) was inoculated with $100 \mathrm{~mL}$ of the seed culture. The temperature was set at $26^{\circ} \mathrm{C}$. The stirrer speed was set to

Table $1{ }^{13} \mathrm{C}$ data of $1\left(175 \mathrm{MHz}\right.$, methanol- $\left.d_{4}\right)$ and $\mathbf{2 - 4}(175 \mathrm{MHz}$, chloroform- $d$ )

\begin{tabular}{llccc}
\hline & $\mathbf{1}$ & $\mathbf{3}$ & $\mathbf{4}$ \\
\hline 1 & $60.5, \mathrm{CH}$ & $60.3, \mathrm{CH}$ & $63.1, \mathrm{CH}$ & $54.3, \mathrm{CH}$ \\
2 & $29.9, \mathrm{CH}_{2}$ & $25.0, \mathrm{CH}_{2}$ & $72.5, \mathrm{CH}$ & $30.3, \mathrm{CH}_{2}$ \\
3 & $40.6, \mathrm{CH}_{2}$ & $41.7, \mathrm{CH}_{2}$ & $47.3, \mathrm{CH}_{2}$ & $40.1, \mathrm{CH}_{2}$ \\
4 & $50.8, \mathrm{C}$ & $49.8, \mathrm{C}$ & $45.1, \mathrm{C}$ & $49.5, \mathrm{C}$ \\
5 & $49.2, \mathrm{CH}_{2}$ & $46.5, \mathrm{CH}_{2}$ & $47.7, \mathrm{CH}_{2}$ & $46.4, \mathrm{CH}_{2}$ \\
6 & $132.4, \mathrm{C}$ & $123.3, \mathrm{C}$ & $123.4, \mathrm{C}$ & $123.1, \mathrm{C}$ \\
7 & $141.1, \mathrm{C}$ & $162.6, \mathrm{C}$ & $162.4, \mathrm{C}$ & $162.7, \mathrm{C}$ \\
8 & $73.4, \mathrm{C}$ & $73.8, \mathrm{C}$ & $73.5, \mathrm{C}$ & $73.7, \mathrm{C}$ \\
9 & $42.8, \mathrm{CH}$ & $80.0, \mathrm{C}$ & $34.9, \mathrm{CH}^{-}$ & $49.9, \mathrm{CH}^{-}$ \\
10 & $37.8, \mathrm{CH}_{2}$ & $43.2, \mathrm{CH}_{2}$ & $37.2, \mathrm{CH}_{2}$ & $31.6, \mathrm{CH}_{2}$ \\
11 & $30.9, \mathrm{CH}_{2}$ & $28.3, \mathrm{CH}_{2}$ & $30.3, \mathrm{CH}_{2}$ & $30.0, \mathrm{CH}_{2}$ \\
12 & $24.9, \mathrm{CH}_{3}$ & $23.1, \mathrm{CH}_{3}$ & $24.7, \mathrm{CH}_{3}$ & $23.8, \mathrm{CH}_{3}$ \\
13 & $59.4, \mathrm{CH}_{2}$ & $169.0, \mathrm{C}$ & $168.4, \mathrm{C}$ & $168.0, \mathrm{C}$ \\
14 & $11.0, \mathrm{CH}_{3}$ & $13.4, \mathrm{CH}_{3}$ & $13.7, \mathrm{CH}_{3}$ & $13.7, \mathrm{CH}_{3}$ \\
15 & $19.8, \mathrm{CH}_{3}$ & $28.7, \mathrm{CH}_{3}$ & $21.2, \mathrm{CH}_{3}$ & $66.2, \mathrm{CH}_{2}$ \\
\hline
\end{tabular}


Table $2{ }^{1} \mathrm{H}$ data of $\mathbf{1}\left(700 \mathrm{MHz}\right.$, methanol- $\left.d_{4}\right)$ and 2-4 (700 MHz, chloroform- $d$ )

\begin{tabular}{lllll}
\hline & $\mathbf{1}$ & $\mathbf{2}$ & $\mathbf{3}$ & $\mathbf{4}$ \\
\hline 1 & $1.66, \mathrm{~m}$ & $2.07, \mathrm{~m}$ & $1.90, \mathrm{~m}$ & $1.99, \mathrm{td}(7.7,2.6)$ \\
$2 \alpha$ & $1.39, \mathrm{~m}$ & $1.62, \mathrm{~m}$ & $4.33, \mathrm{ddd}(10.3,7.7,6.0)$ & $1.46, \mathrm{~m}$ \\
$2 \beta$ & $1.71, \mathrm{~m}$ & $1.71, \mathrm{~m}$ & $1.77, \mathrm{~m}$ \\
$3 \alpha$ & $1.52, \mathrm{~m}$ & $1.61, \mathrm{~m}$ & $1.56, \mathrm{~m}$ \\
$3 \beta$ & $1.65, \mathrm{~m}$ & $1.64, \mathrm{~m}$ & $1.58, \mathrm{dd}(12.5,10.3)$ & $1.63, \mathrm{~m}$ \\
$5 \alpha$ & $2.13, \mathrm{dq}(16.0,1.7)$ & $2.36, \mathrm{dd}(16.0,1.7)$ & $1.92, \mathrm{dd}(12.5,6.0)$ & $2.35, \mathrm{dq}(16.2,1.7)$ \\
$5 \beta$ & $2.37, \mathrm{dq}(16.0,2.2)$ & $2.53, \mathrm{dd}(16.0,2.2)$ & $2.39, \mathrm{dd}(16.5,1.7)$ & $2.54, \mathrm{dq}(16.2,2.2)$ \\
9 & $1.47, \mathrm{~m}$ & & $2.52, \mathrm{dd}(16.5,2.2)$ & $1.73, \mathrm{~m}$ \\
$10 \alpha$ & $1.77, \mathrm{~m}$ & $2.10, \mathrm{~m}$ & $1.85, \mathrm{~m}$ \\
$10 \beta$ & $1.26, \mathrm{~m}$ & $1.76, \mathrm{~m}$ & $1.85, \mathrm{~m}$ & $1.49, \mathrm{~m}$ \\
$11 \alpha$ & $1.63, \mathrm{~m}$ & $1.76, \mathrm{~m}$ & $1.35, \mathrm{~m}$ & $1.68, \mathrm{~m}$ \\
$11 \beta$ & $1.56, \mathrm{~m}$ & $1.85, \mathrm{~m}$ & $1,68, \mathrm{~m}$ & $1.64, \mathrm{~m}$ \\
12 & $1.03, \mathrm{~s}$ & $1.50, \mathrm{~m}$ & $1.68, \mathrm{~m}$ & $1.05, \mathrm{~s}$ \\
13 & $4.04, \mathrm{~s}$ & $1.08, \mathrm{~s}$ & $1.02, \mathrm{~s}$ & $2.03, \mathrm{dd}(2.2,1.7)$ \\
14 & $1.61, \mathrm{dd}(2.2,1.7)$ & & & $3.64, \mathrm{dd}(10.5,5.8)$ \\
15 & $0.99, \mathrm{~d}(6.5)$ & $2.06, \mathrm{dd}(2.2,1.7)$ & $2.05, \mathrm{dd}(2.2,1.7)$ & $3.55, \mathrm{dd}(10.5,7.5)$ \\
\hline
\end{tabular}

$150 \mathrm{rpm}$, aeration rate was set to $0.07 \mathrm{vvm}$ and remained constant during fermentation. The culture was harvested after 7 days as sugars (sucrose, fructose) were depleted. Thereafter, the mycelium was separated from the culture fluid by vacuum filtration to yield a total amount of $525 \mathrm{~g}$ wet biomass, which was later extracted with $1.8 \mathrm{~L}$ acetone in an ultrasonic bath for $1 \mathrm{~h}$. The acetone extract was filtered and evaporated to yield an aqueous phase, which was further processed by extraction with $3 \times 100 \mathrm{~mL}$ ethyl acetate in a separating funnel. Subsequently the organic phases were combined and evaporated to yield $221 \mathrm{mg}$ of oily mycelial crude extract (ME) in total.

The culture filtrate was extracted by $2 \%$ XAD-16 (200 g) over $2 \mathrm{~h}$ at room temperature. The XAD was separated by filtration and extracted with methanol $(500 \mathrm{~mL})$. The extract was evaporated to yield an aqueous phase, which was further processed by extraction with $3 \times 50 \mathrm{~mL}$ ethyl acetate. The combined organic extracts were filtrated over Strata X column to yield $643 \mathrm{mg}$ crude extract.

The crude extract was subjected to silica gel chromatography using gradient elution with portions of dichloromethane/methanol mixtures $(250 \mathrm{~mL})$ of $100 / 0$, 99/1, 98/2, 97/3, 95/5, 90/10, 85/15, 80/20, 70/30, 50/50, 25/75, 0/100 to give 12 fractions. Fraction 2 (303 mg) was fractionized with preparative HPLC (PLC 2020, Gilson, Middleton, USA). A VP Nucleodur $\mathrm{C}_{18}$ ec column $(150 \times 40 \mathrm{~mm}, 7 \mu \mathrm{m}$; Macherey-Nagel) was used as stationary phase. The mobile phase was composed of deionised water (Milli-Q) as solvent A and methanol (MeOH)

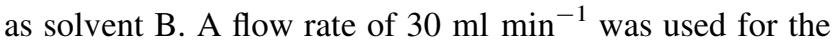

following gradient: $10-80 \%$ solvent $\mathrm{B}$ in $30 \mathrm{~min}$, afterwards in $5 \mathrm{~min}$ to $100 \% \mathrm{~B}$, isocratic conditions at $100 \%$ for $10 \mathrm{~min}$. UV detection was carried out at 210 and $254 \mathrm{~nm}$ and fractions were collected and combined according to the observed peaks. $2(0.9 \mathrm{mg})$ was obtained at a retention time $(\mathrm{RT})=30.7-31.0 \mathrm{~min}$.

Fraction 5 (89 $\mathrm{mg}$ ) was subjected to preparative HPLC as described above (but gradient: $30-100 \%$ solvent B in $30 \mathrm{~min}$, isocratic conditions at $100 \%$ for $10 \mathrm{~min}$ ) to yield $3(0.6 \mathrm{mg})$ at a $\mathrm{RT}=18.7-21.7 \mathrm{~min}$ and $4(0.3 \mathrm{mg})$ at $\mathrm{RT}=14.3-15.5 \mathrm{~min}$.

Fraction 1 (242 $\mathrm{mg})$ subjected to preparative HPLC as described above (but gradient: 0-70 \% solvent B in $40 \mathrm{~min}$, afterwards in $5 \mathrm{~min}$ to $100 \% \mathrm{~B}$, isocratic conditions at $100 \%$ for $5 \mathrm{~min})$ to yield $7(0.8 \mathrm{mg})$ and $\mathbf{8}$ at a RT $=19.6-20.2$ and $\mathrm{RT}=17.7-18.6 \mathrm{~min}$, respectively. Fractions from 35.1 to $36.4 \mathrm{~min}$ were combined and fractionated again (gradient: $40-80 \%$ acetonitril in $40 \mathrm{~min}$, afterwards in $5 \mathrm{~min}$ to $100 \%$ ACN, isocratic conditions at $100 \%$ for $5 \mathrm{~min}$, VP Nucleodur $\mathrm{C}_{18}$ ec column $(250 \times 21 \mathrm{~mm}, 7 \mu \mathrm{m}$; Macherey-Nagel $)$ to yield 6 (2.4 $\mathrm{mg})$ at a $\mathrm{RT}=20.5-22 \mathrm{~min}$.

Rickinic acid A (2): amorphous powder, $[\alpha]_{\mathrm{D}}^{25}+2.2(c 0.02$ $\left.\mathrm{CHCl}_{3}\right) ; \mathrm{UV}(\mathrm{MeOH}) \lambda_{\max }(\log \varepsilon) 234 \mathrm{~nm}(4.7) ;{ }^{1} \mathrm{H}(700 \mathrm{MHz})$ and ${ }^{13} \mathrm{C}(175 \mathrm{MHz}) \mathrm{NMR}$ data (chloroform- $d$ ), see Tables 1 and 2; ESIMS: $m / z$ 250.95 [M+H] $]^{+}, 248.86[\mathrm{M}-\mathrm{H}]^{-}$; HRESIMS: $m / z, 251.1649$ (calcd for $\mathrm{C}_{15} \mathrm{H}_{23} \mathrm{O}_{3},[\mathrm{M}+\mathrm{H}]^{+}, 251.1642$ ).

Rickinic acid B (3): amorphous powder, $[\alpha]_{\mathrm{D}}^{25}+12$ (c $\left.0.1 \mathrm{CHCl}_{3}\right)$; UV (MeOH) $\lambda_{\max }(\log \varepsilon) 234 \mathrm{~nm}(4.5) ;{ }^{1} \mathrm{H}$ $(700 \mathrm{MHz})$ and ${ }^{13} \mathrm{C}(175 \mathrm{MHz}) \mathrm{NMR}$ data (chloroform- $d$ ), see Tables 1 and 2; ESIMS: $m / z 251.02[\mathrm{M}+\mathrm{H}]^{+}, 248.96$ 
$[\mathrm{M}-\mathrm{H}]^{-}$; HRESIMS: $m / z \quad 251.1648$ (calcd for $\left.\mathrm{C}_{15} \mathrm{H}_{23} \mathrm{O}_{3},[\mathrm{M}+\mathrm{H}]^{+}, 251.1642\right)$.

Rickinic acid $\mathrm{C}(4)$ : amorphous powder, $[\alpha]_{\mathrm{D}}^{25}+11$ (c $0.1 \mathrm{CHCl}_{3}$ ); UV (MeOH) $\lambda_{\max }(\log \varepsilon) 220 \mathrm{~nm}(\mathrm{sh}) ;{ }^{1} \mathrm{H}$ $(700 \mathrm{MHz})$ and ${ }^{13} \mathrm{C}(175 \mathrm{MHz}) \mathrm{NMR}$ data (chloroform- $d$ ), see Tables 1 and 2; ESIMS: $m / z$ 233.01 $\left[\mathrm{M}+\mathrm{H}-\mathrm{H}_{2} \mathrm{O}\right]^{+}$, $248.94[\mathrm{M}-\mathrm{H}]^{-}$; HRESIMS: $\mathrm{m} / z 251.1648$ (calcd for $\left.\mathrm{C}_{15} \mathrm{H}_{23} \mathrm{O}_{3},[\mathrm{M}+\mathrm{H}]^{+}, 251.1642\right)$.

Dehydrobotrydienol (6): colorless oil; ${ }^{13} \mathrm{C}$ NMR (chloroform- $d, 125 \mathrm{MHz}) \delta 19.0,26.3,31.1,32.2,40.9,50.4$, 54.0, 58.8, 71.1, 123.1, 130.5, 134.4, 136.4, 144.1, 152.3; HRESIMS: $m / z \quad 257.1517$ (calcd for $\mathrm{C}_{15} \mathrm{H}_{22} \mathrm{O}_{2} \mathrm{Na}$, $\left.[\mathrm{M}+\mathrm{H}]^{+}, 257.1512\right)$; spectroscopic and spectrometric data are in good agreement with the literature [18].

Cyclo(Phe-Pro) (7): colorless oil; ${ }^{13} \mathrm{C}$ NMR (chloroform- $d, 125 \mathrm{MHz}) \delta 22.6,28.4,36.8,45.5,56.2,59.2$, 127.6, 129.1, 129.4, 135.9, 165.1, 169.5; HRESIMS: $m / z$ 245.1297 (calcd for $\mathrm{C}_{14} \mathrm{H}_{17} \mathrm{~N}_{2} \mathrm{O}_{2},[\mathrm{M}+\mathrm{H}]^{+}, 245.1285$ ); spectroscopic and spectrometric data are in good agreement with the literature [19].

Cyclo(Pro-Leu) (8): colorless oil; ${ }^{13} \mathrm{C}$ NMR (chloroform- $d, 125 \mathrm{MHz}$ ) $\delta 21.2,22.8,23.3,24.8,28.2,29.7,38.7$, 45.6, 53.4, 59.0, 166.1, 170.3; HRESIMS: $m / z 211.1461$ (calcd for $\mathrm{C}_{11} \mathrm{H}_{19} \mathrm{~N}_{2} \mathrm{O}_{2},[\mathrm{M}+\mathrm{H}]^{+}, 211.1441$ ); spectroscopic and spectrometric data are in good agreement with the literature [20].

\subsection{Small-Scale Cultivation and Isolation of $\mathbf{5}$ and 9}

Two submerged cultures were grown in each case in $200 \mathrm{~mL}$ YMG medium supplemented with $3 \mathrm{~g}$ talcum powder on a rotary shaker at $140 \mathrm{rpm}$ and $23{ }^{\circ} \mathrm{C}$. Cultures were harvested after 12 days as free glucose was consumed. Afterwards the supernatant was separated from the biomass by vacuum filtration and extracted with $200 \mathrm{~mL}$ ethyl acetate. The organic phases were combined, dried over sodium sulfate and evaporated to yield $50 \mathrm{mg}$ crude extract. The latter was fractionated by RP HPLC using the following conditions: a VP 250/21 Nucleodur100-5 C18 ec column (Macherey-Nagel) equipped with a Kromasil 100 C18 pre-column $(50 \times 20 \mathrm{~mm}, 7 \mu \mathrm{m}$; AkzoNobel $)$ as stationary phase, solvents $\mathrm{A} 1$ and $\mathrm{B} 1$ as mobile phase, linear gradient from 20 to $70 \%$ solvent B1 in 40 min, then from 70 to $100 \% \mathrm{~B} 1$ in $5 \mathrm{~min}$, followed by $10 \mathrm{~min}$ isocratic conditions, flow rate of $15 \mathrm{ml} / \mathrm{min}$. Compound 5 $(1.4 \mathrm{mg})$ was obtained at a $\mathrm{RT}=33.0 \mathrm{~min}$ and $\mathbf{9}(1.5 \mathrm{mg})$ at a $\mathrm{RT}=35.0 \mathrm{~min}$.

Botryenanol (5): Colorless oil; ${ }^{13} \mathrm{C}$ NMR (chloroform- $d$, $125 \mathrm{MHz}) \delta$ 20.9, 21.4, 23.8, 29.1, 29.3, 36.8, 39.1, 51.8, 54.2, 58.5, 70.5, 71.9, 139.0, 164.7, 170.3, 192.6; HRESIMS: $m / z 317.1728$ (calcd for $\mathrm{C}_{17} \mathrm{H}_{26} \mathrm{O}_{4} \mathrm{Na},[\mathrm{M}+\mathrm{H}]^{+}$, 317.1723); spectroscopic and spectrometric data are in good agreement with the literature [17].
(+)-Ramulosin (9): Colorless amorphous powder, $[\alpha]_{\mathrm{D}}^{25}$ $+12\left(c 0.1 \mathrm{CH}_{3} \mathrm{OH}\right) ;{ }^{13} \mathrm{C}$ NMR (chloroform- $\left.d, 125 \mathrm{MHz}\right) \delta$ 21.0, 21.8, 29.1, 29.6, 33.0, 37.5, 76.6, 96.8, 171.9, 174.8; HRESIMS: $m / z, 183.1026$ (calcd for $\mathrm{C}_{10} \mathrm{H}_{15} \mathrm{O}_{3},[\mathrm{M}+\mathrm{H}]^{+}$, 183.1016); spectroscopic and spectrometric data are in good agreement with the literature [21].

\subsection{Biological Assays}

Antibacterial, antifungal and cytotoxic assays were performed as described by Surup et al. [35].

Acknowledgments We thank Andreas Glatt for his preliminary work on the optimization of secondary metabolite production with talcum powder, Wera Collisi for conducting the bioassays, Philine Wotsch and Anke Skiba for assistance in the mycological lab, and Christel Kakoschke for recording NMR spectra. For HRESIMS measurements we are grateful to Aileen Teichmann and Heinrich Steinmetz. Jacques Fournier is gratefully acknowledged for sending us the fungal material. His collection trip in Martinique has benefited from "Investissements d'Avenir" Grants of the ANR (CEBA ANR10-LABX-0025, CNRS Cayenne and Toulouse).

Conflict of interest The authors declare no conflicts of interests.

Open Access This article is distributed under the terms of the Creative Commons Attribution 4.0 International License (http://creativecommons.org/licenses/by/4.0/), which permits unrestricted use, distribution, and reproduction in any medium, provided you give appropriate credit to the original author(s) and the source, provide a link to the Creative Commons license, and indicate if changes were made.

\section{References}

1. M. Stadler, D.N. Quang, A. Tomita, T. Hashimoto, Y. Asakawa, Mycol. Res. 110, 811-820 (2006)

2. F. Surup, K.I. Mohr, R. Jansen, M. Stadler, Phytochemistry 95, 252-258 (2013)

3. X.N. Wang, W.Y. Huang, J.C. Ju, C.Y. Li, J.K. Liu, Biochem. Syst. Ecol. 54, 157-159 (2014)

4. E. Kuhnert, S. Heitkämper, J. Fournier, F. Surup, M. Stadler, Fungal Biol. 118, 242-252 (2014)

5. E. Kuhnert, F. Surup, E.B. Sir, C. Lambert, K.D. Hyde, A.I. Hladki, A.I. Romero, M. Stadler, Fungal Divers. 71, 165-184 (2015)

6. E.B. Sir, E. Kuhnert, F. Surup, K.D. Hyde, M. Stadler, Mycol. Prog. 14, 28 (2015)

7. M. Stadler, V. Hellwig, Recent Res. Dev. Phytochem. 9, 41-93 (2005)

8. F. Surup, E. Kuhnert, E. Lehmann, S. Heitkämper, K.D. Hyde, J. Fournier, M. Stadler, Mycology 5, 110-119 (2014)

9. M. Daferner, S. Mensch, T. Anke, O. Sterner, Z. Naturforsch, C 54, 474-480 (1999)

10. C.J. Smith, N.R. Morin, G.F. Bills, A.W. Dombrowski, G.M. Salituro, S.K. Smith, A. Zhao, D.J. MacNeil, J. Org. Chem. 67, 5001-5004 (2002)

11. J. Pinon, P.D. Manion, Eur. J. For. Pathol. 21, 202-209 (1991)

12. T. Ando, K. Yoshida, M. Okuhara, J. Antibiot. 41, 31-35 (1988)

13. D.R. Jayanetti, Q. Yue, G.F. Bills, J.B. Gloer, J. Nat. Prod. 78, 396-401 (2015) 
14. X.D. Qin, H.J. Shao, Z.J. Dong, J.K. Liu, J. Antibiot. 61, 556-562 (2008)

15. E. Kuhnert, F. Surup, V. Wiebach, S. Bernecker, M. Stadler, Phytochemistry 117, 116-122 (2015)

16. L.A. Paquette, R.A. Roberts, G.J. Drtina, J. Am. Chem. Soc. 106, 6690-6693 (1984)

17. I.G. Collado, R. Hernández-Galán, V. Prieto, J.R. Hanson, L.G. Rebordinos, Phytochemistry 41, 513-517 (1996)

18. R. Durán-Patrón, R. Hernández-Galán, I. Collado, J. Nat. Prod. 63, 182-184 (2000)

19. M. Tullberg, M. Grotli, K. Luthman, Tetrahedron 62, 7484-7491 (2006)

20. M. Soledade, C. Pedras, Y. Yu, J. Liu, Y.A. Tandron-Moya, Z. Naturforsch. C 60, 717-722 (2005)

21. D.B. Stierle, A.A. Stierle, A. Kunz, J. Nat. Prod. 61, 1277-1278 (1998)

22. Y. Amakura, K. Kondo, H. Akiyama, H. Ito, T. Hatano, T. Yoshida, T. Maitani, J. Food Hyg. Soc. Jpn. 47, 178-181 (2006)

23. F. Bohlmann, J. Jakupovic, Phytochemistry 19, 259-265 (1980)

24. P. Weyerstahl, H. Marschall, I. Seelmann, J. Jakupovic, Eur. J. Org. Chem. 6, 1205-1212 (1998)
25. B. Tudzynski, Appl. Microbiol. Biotechnol. 66, 597-611 (2005)

26. R.M. Coates, Z. Ho, M. Klobus, S.R. Wilson, J. Am. Chem. Soc. 118, 9249-9254 (1996)

27. I.G. Collado, A.J.M. Sánchez, J.R. Hanson, Nat. Prod. Rep. 24, 674-686 (2007)

28. K. Krohn, J. Dai, U. Flörke, H.J. Aust, S. Dräger, B. Schulz, J. Nat. Prod. 68, 400-405 (2005)

29. J.R. Anderson, L.E. Edwards, J. Chem. Soc. Perkin Trans. 1, 2185-2192 (1983)

30. W.F. Hendershot, C.W. Hesseltine, T.G. Pridham, R.G. Benedict, R.W. Jackson, Arch. Biochem. Biophys. 96, 166-170 (1962)

31. Y.S. Chen, Bull. Chem. Soc. Jpn 24, 372-381 (1960)

32. S. Halecker, F. Surup, E. Kuhnert, K.I. Mohr, N.L. Brock, J.S. Dickschat, C. Junker, B. Schulz, M. Stadler, Phytochemistry 100, 86-91 (2014)

33. E. Kuhnert, J. Fournier, D. Peršoh, J.J. Luangsa-ard, M. Stadler, Fungal Divers. 64, 181-203 (2014)

34. M. Stadler, T. Læssøe, J. Fournier, C. Decock, B. Schmieschek, H.V. Tichy, D. Peršoh, Stud. Mycol. 77, 1-143 (2014)

35. F. Surup, B. Thongbai, E. Kuhnert, E. Sudarman, K.D. Hyde, M. Stadler, J. Nat. Prod. 78, 934-938 (2015) 